\title{
Contracampo
}

\section{Câmera intradiegética e maneirismo em obras de George A. Romero e Brian De Palma}

\author{
Intra-diegetic camera and mannerism in films by \\ George A. Romero and Brian De Palma
}

Laura Loguercio Cánepa

lauracanepa@anhembimorumbi.edu.br

Doutora em Multi meios pela Universidade Estadual de Campinas (UNICAMP). Coordenadora do Programa de Pós-Graduação em Comunicação e Docente no curso de Graduação em Cinema e Audiovisual da Universidade Anhembi Morumbi.

Rodrigo Carreiro rcarreiro@gmail.com

Mestre e Doutor em Comunicação pela Universidade Federal de Pernambuco (UFPE). Professor do Programa de Pós-Graduação em Comunicação e Coordenador do Bacharelado em Cinema e Audiovisual da UFPE.

Ao citar este artigo, utilize a seguinte referência bibliográfica

CÁNEPA, Laura Loguercio; CARREIRO, Rodrigo. Câmera intradiegética e maneirismo em obras de George A. Romero e Brian De Palma. In: Revista Contracampo, v. 31, n. 1, ed. dezembro-março ano 2014. Niterói: Contracampo, 2014. Págs: 101-121.

DOI: $10.5327 / \mathrm{Z22382577201400310673}$

Enviado em: 03 de jul. de 2014

Aceito em: 19 de out. de 2014

\section{PPGCOM}

Edição 31/2014

Transmidiação e cultura participativa

Contracampo

e-ISSN 2238-2577
Niterói (RJ), v. 31, n. 1, dez-mar/2014

www.uff.br/contracampo

A Revista Contracampo é uma revista eletrônica do Programa de PósGraduação em Comunicação da Universidade Federal Fluminense e tem como objetivo contribuir para a reflexão crítica em torno do campo midiático, atuando como espaço de circulação da pesquisa e do pensamento acadêmico. 


\section{Resumo}

Em 2007, George A. Romero e Brian De Palma realizaram experimentos de ficção com o uso do recurso ao qual chamaremos neste artigo de câmera intradiegética, que consiste na construção de narrativas audiovisuais através de registros feitos pelos personagens ou por dispositivos pertencentes ao universo ficcional. Os longas "Diário dos mortos" e "Guerra sem cortes", de Romero e De Palma, respectivamente, converteram-se em marcos para o cinema de ficção construído a partir desse recurso, justamente no ano em que aumentou massivamente a quantidade de filmes que adotaram a câmera intradiegética, originando um filão de cinema de aventura e horror que ficaria conhecido como found footage por usar, na maioria das vezes, a premissa do "registro encontrado" para justificar a incorporação dos equipamentos de captação à narrativa. Neste artigo, sugerimos observar esse recurso como uma abordagem maneirista na ficção contemporânea, que tem, nas obras de Romero e De Palma, exemplos fundamentais.

Palavras-chave: câmera intradiegética; found footage; Maneirismo; George A. Romero; Brian De Palma.

\section{Abstract}

In 2007, George A. Romero and Brian De Palma conducted experiments in fiction feature film with the use of the resource that we will call intra-diegetic camera, which consists in the construction of audiovisual narratives through footage made by characters or devices within the fictional universe. The feature films "Diary of the dead" and "Redacted", made by Romero and De Palma, respectively, have become landmarks for fiction cinema built from this resource, in the very same year in which the number of movies made with intra-diegetic cameras became massive, creating a trend of adventure and horror films that got known as found footage for using, in most cases, the premise of "found register" to justify the incorporation of recording devices inside the narrative tissue. In this article, we try to read this resource as a mannerist approach in contemporary fiction, which has, in the works of Romero and De Palma, prime examples.

Keywords: intra-diegetic camera; found footage; Mannerism; George A. Romero; Brian De Palma. 


\section{Introdução}

$\checkmark$ ilmes de ficção codificados como found footages (ou "filmes encontrados"), frequentemente devedores ao estilo documental, constituem hoje um fenômeno massivo de produção e consumo cinéfilo no campo do cinema de horror e aventura. A solução narrativa do "documentário encontrado" usada em enredos de ficção ${ }^{1}$, e trabalhada em lançamentos esparsos que começaram a ocorrer nos anos 1970, teve seu potencial midiático intensificado na virada do século, após o sucesso massivo de "A Bruxa de Blair" (The Blair Witch Project, Daniel Myrick e Eduardo Sánchez, 1999), filme que trazia registros alegadamente reais do material captado por três jovens desaparecidos durante as filmagens de um documentário. No entanto, apesar da grande bilheteria e da atenção recebida nos meios jornalístico e acadêmico, alguns anos se passaram até que a ideia do filme encontrado constituísse uma prática estilística regular no cinema de ficção.

O momento crucial para esse fenômeno parece ter ocorrido ao longo do ano de 2007. No intervalo de oito anos entre a capa que a revista Time dedicou ao filme de Sánchez e Myrick e a temporada cinematográfica de verão de 2007, um número razoável de ficções feitas a partir de falsos registros de documentaristas ganhou as telas. Entre elas, estão o thriller britânico "The last horror movie” (Julian Richards, 2003), o horror japonês "Noroi" (Kôji Shiraishi, 2005), o drama dinamarquês "Offscreen" (Christopher Boe, 2006) e o falso documentário estadunidense "Poughkeepsie tapes” (John Erick Dowdle, 2007). Esses filmes, entretanto, ainda não constituíam um estilo consolidado de filmagem.

Então, em 2007, assistiu-se à produção de um número muito maior de longas-metragens ficcionais codificados como found footage, incluindo três títulos que alcançaram grande repercussão. Todos eles deixaram em segundo plano os recursos de estilo do documentário, dando mais atenção às captações ditas “acidentais" e à estética amadora, transformando-se em referências obrigatórias para a produção que viria depois: o espanhol "[Rec]" (Paco Plaza e Jaume Balagueró, 2007), que trazia o material deixado por uma equipe de TV surpreendida por uma praga de zumbis; o filme de monstro “Cloverfield” (Matt Reeves, 2008), produção hollywoodiana que se propunha como um vídeo amador feito por um jovem estudante; e

Evitamos usar o termo mockumentary, pois o uso de recursos do documentário parece ter, nesses filmes, o objetivo apenas de justificar a presença de equipamentos de captação ao alcance das personagens. 
o primeiro título da franquia "Atividade paranormal"2 (Oren Peli, 2007), suposto registro caseiro feito por um casal para investigar fenômenos sobrenaturais.

A boa receptividade do público e os lucros obtidos por esses títulos poderiam explicar o aumento na produção e circulação de filmes de ficção que, como eles, foram codificados como found footage. Há, contudo, outras variáveis. Elas incluem o baixo custo de produção (pois não é necessário construir cenários ou pagar cachês a estrelas, já que esse tipo de ficção funciona tão melhor quanto mais comum for sua aparência e menos conhecidos forem seus atores), a proliferação de dispositivos de registro de imagem e som em alta definição e toda uma cultura audiovisual que combina o consumo regular de vídeos amadores e a exposição da intimidade, através de plataformas multimídia e da disseminação de reality shows.

Tudo isso sugere que a consolidação do falso found footage consiste de uma das muitas faces de um fenômeno cultural amplo, que tem sido examinado por pesquisadores a partir de diferentes abordagens teóricas (ODIN, 1995; FELDMAN, 2008; BRASIL; MIGLIORIN, 2010). A ressignificação de filmes de família, o uso de vídeos disponíveis na Internet dentro de trabalhos audiovisuais, a popularidade de imagens amadoras, os fenômenos midiáticos nascidos de vídeos caseiros postados no YouTube, a forte e crescente tendência da aceitação de (e até mesmo preferência por) imagens que contenham erros técnicos e a espetacularização de imagens e sons da intimidade constituem temas que integram um debate mais amplo sobre novos regimes de visualidade que privilegiam imagens amadoras.

Esses novos regimes de visualidade, portanto, ajudaram os found footages ficcionais a cair nas graças de cineastas de todo o planeta, em países tão diferentes como Índia, Noruega, Costa Rica, Alemanha, Argentina, Turquia, Austrália, Sérvia, México, Bélgica, Japão e EUA. O tamanho do fenômeno impressiona: uma consulta a listas publicadas por usuários do site Internet Movie Database torna possível confirmar o lançamento, desde 2007, de pelo menos 360 títulos de ficção found footage — a maioria deles, de horror. Além deles, também recorreram a essa estratégia pelo menos quatro minisséries de TV, entre elas, "Lost tapes" (2009), do canal Animal Planet; quatro jogos eletrônicos populares, inclusive "Slender: the eight pages" (2012) e um grande número de webséries populares no YouTube, como "Marble hornets" (2012-2014) e "Mr. Creepypasta's story time” (2012-2014).

2 O filme circulou em festivais até ser lançado comercialmente em 2009, quando se tornou fenômeno de bilheteria, originando uma franquia hoje com cinco episódios. 
Desde 2007, portanto, o found footage de ficção tem sido combatido e celebrado em diversos círculos de críticos, pesquisadores e cinéfilos. A abordagem dominante desses debates associa os filmes a um novo gênero ou subgênero fílmico. Nesse sentido, estaria próximo da noção de gênero fílmico adjetivo, conforme proposto por Altman (1999).

A descrição que Altman faz do percurso histórico de um gênero fílmico adjetivo corresponde ao que vem ocorrendo com o found footage ficcional. Mas, ainda que a maioria desses filmes seja de horror, há exemplos de títulos que operam dentro de outros gêneros, como a ficção-científica adolescente "Poder sem Limites" (Chronicle, Josh Trank, 2012), a comédia "Projeto X - uma festa fora de controle" (Project X, Nima Nourizadeh, 2012), o filme-catástrofe "The Bay" (Barry Levenson, 2012) e a aventura infanto-juvenil "Projeto Dinossauro" (The Dinosaur Project, Sid Bennett, 2012), além do curioso “Tá dando onda" (Surf's up, Ash Branon e Chris Bruck, EUA, 2007), comédia de animação que parodia a estilística documental a partir de uma situação diegética que simula um documentário feito por uma equipe de pinguins surfistas.

Quando consideramos esses filmes, vemos que a noção de gênero found footage ainda carece de amadurecimento. No entanto, uma característica mais básica sobressai desse conjunto: o fato de todos fazerem uso do recurso da câmera intradiegética ${ }^{3}$, isto é, suas narrativas são construídas através de registros feitos pelos próprios personagens ou por aparelhos que pertencem ao universo fictício, num tour de force estilístico que foge aos padrões da câmera ubíqua e onisciente do cinema de ficção convencional. Sem dúvida, procedimentos de câmera intradiegética são recorrentes na história do cinema de ficção, e filmes fundamentais como "Janela indiscreta" (Rear Window, Alfred Hitchcock, 1954) e “A tortura do medo" (Peeping Tom, Michael Powell, 1960), entre muitos outros, já fizeram uso desse recurso (MACHADO, 2007). A diferença destes para os filmes aqui tratados está no fato de, nos últimos, a presença da câmera intradiegética ser um recurso constante ao longo de toda a narrativa, o que configura uma espécie de jogo mimético com a estilística do documentário que dá aos produtos resultantes características específicas (CARREIRO, 2013).

Neste ensaio, buscamos propor uma leitura alternativa desses filmes, sugerindo observá-los não a partir de teorias de gênero fílmico — a abordagem teórica predominante atualmente - , mas da perspectiva da estilística cinematográfica, propondo a instituição

3 Optou-se, neste artigo, por usar o termo "câmera intradiegética" em lugar de "diegética" (CARREIRO, 2013) para acompanhar o termo mais usado em publicações sobre narratologia em língua portuguesa. 
da câmera intradiegética como uma abordagem "maneirista" da ficção audiovisual contemporânea. Como estudos de caso, selecionamos dois títulos lançados no estratégico ano de 2007, ambos dirigidos por veteranos cujas obras que figuram entre as mais influentes do cinema comercial nos últimos 50 anos. Os filmes "Diário dos mortos" (Diary of the dead, George A. Romero) e "Guerra sem cortes" (Redacted, Brian De Palma) foram fracassos de bilheteria, mas acabaram por se converter em marcos estilísticos importantes para o cinema de ficção construído a partir do recurso da câmera intradiegética.

\section{Notas sobre o maneirismo e seus novos dispositivos}

Discutir o found footage ficcional como procedimento maneirista significa deslocar o debate do terreno dos gêneros para o reino da estilística - o estudo do estilo, conceito definido por Bordwell, no cinema, como o "uso sistemático e significativo de técnicas dessa mídia [encenação, fotografia, montagem e desenho de som] em uma obra" (2013, p. 17). Mas, para levar a cabo esse deslocamento conceitual, é preciso começar estabelecendo uma definição de maneirismo cinematográfico.

Termo adaptado ao cinema a partir de um conceito surgido após o Renascimento na história da arte europeia, o Maneirismo consistiu em um movimento artístico que, segundo Hauser, "chegou tão tarde ao primeiro plano da investigação sobre a história da arte, que o veredito depreciativo implícito em seu próprio nome ainda é, com frequência, aceito como adequado" (2000, p. 367). Para ele, "só depois que o conceito de maneirista estiver completamente separado do de 'afetado' e 'amaneirado' é que obteremos uma categoria que possa ser usada na investigação histórica” (2000, p. 367).

O maneirismo, segundo a descrição de Hauser, "começa decompondo a estrutura renascentista [unitária] de espaço e desmembrando a cena a ser representada em partes separadas" (2000, p. 373). Isso permite que diferentes valores espaciais e possibilidades de movimento predominem nas várias seções do quadro. Gombrich descreve sucintamente esses procedimentos como "quebra-cabeças pictóricos" (1999, p. 361). Para ele, o maneirismo mostra, através de distorções formais, "que a solução clássica da perfeita harmonia não é a única concebível — que existem outros modos menos diretos para obter efeitos interessantes aos olhos dos amantes da arte" (1999, p. 361). 
Shearman sugere que esses efeitos interessantes poderiam ser alcançados através da "ideia de que complexidade e redundância são belas, que o virtuosismo deve ser cultivado e que a arte pode ser artificial" (1967, p. 186). O que todos os autores tentam demonstrar é que a distorção do modelo renascentista observada nas obras maneiristas não significa uma imitação mal feita de um modelo precedente, como o termo poderia sugerir. Para Hauser, essas distorções maneiristas eram condicionadas por um novo espírito, "profundamente não-clássico" (2000, p. 370). Em outras palavras, diz ele, "estamos lidando com um estilo autoconsciente, que baseia suas formas não tanto num determinado objeto quanto na arte de sua época precedente" (HAUSER, 2000, p. 370).

A transposição da ideia de maneirismo para o cinema exige adaptações. Ela surgiu como consequência do fim do classicismo hollywoodiano e tem, como descreve Oliveira Júnior, a característica de composição de “imagens 'de segundo grau' [...] que retomam outras imagens e por isso mesmo, muitas vezes dependem de um conhecimento prévio da história do cinema e/ou dos seus códigos ficcionais" (2013, p. 119). Como descreve o autor, a encenação maneirista "se notabiliza por construções rebuscadas, enquadramentos labirínticos, referências à história da arte, dispositivos ópticos elaborados" (2013, p. 119).

Lançada em 1985 em dossiê publicado nos Cahiers du Cinéma, a noção de um cinema maneirista reuniu em torno do conceito um grupo de diretores diferentes entre si: Wim Wenders, Dario Argento, Raul Ruiz e De Palma estariam entre os adeptos dessa nova estética, marcada, segundo analogia proposta por Alan Bergala, pela consciência de que "uma certa perfeição havia sido atingida pelos mestres que lhes haviam precedido" (apud OLIVEIRA JÚNIOR, 2013, p. 123). Para eles, então, tratava-se de recuperar certos gêneros no momento em que já não dialogavam com o público inocentemente:

A imagem maneirista, segundo Delorme, é aquela que se propõe não exatamente ao remake [...] nem à sua reprise [...], mas à anamarfose, isto é, ao estudo visual sistemático e obsessivo de um motivo magistral. [...] O que move o maneirista é seu desejo de perturbar sistematicamente a referência primeira, de refilmar o plano original de todas as formas e em todos os sentidos (OLIVEIRA JÚNIOR, 2013, p. 124-125).

Mais tarde, a ideia foi recuperada por Bordwell (2006), com a diferença de que o pesquisador propôs um corpus mais largo de cineastas maneiristas, formado principalmente 
por diretores ligados a Hollywood a partir dos anos 1970: de Ridley Scott a Robert Zemeckis, passando por Sam Raimi, Quentin Tarantino e os irmãos Wachowski. "Como pintar o corpo humano após Leonardo, Rafael e Michelangelo?”, questiona Bordwell (2006, p. 188), imaginando o dilema dos pintores do século XVI ao perceberem que a geração predecessora havia alcançado um domínio das proporções harmônicas da natureza difícil de superar. "Como contar uma história no cinema de modo inovador após Ford, Hawks, Hitchcock e Welles?" (BORDWELL, 2006, p. 188), pergunta ele, fechando a analogia e providenciando a resposta:

Uma opção é correr atrás do novo através do investimento em pinceladas ousadas e tours de force; trocar harmonia por energia, calma por agitação, proporção por selvageria. Ler historiadores da arte descrevendo o Maneirismo é ecoar qualidades que vejo no cinema americano pós-1960. (BORDWELL, 2006, p. 118).

Esse movimento maneirista em direção a uma estilística agressiva e autorreferente foi nomeado por Bordwell (2006, p. 119) de "continuidade intensificada". Ele propôs que os diretores adeptos desse estilo mais virtuoso não estavam criando uma nova poética da imagem, mas aguçando os princípios gerais da continuidade clássica, submetidos a um processo contínuo de intensificação. Para Bordwell, ao romperem com o objetivo de camuflar a instância narrativa, os cineastas gradualmente passaram a chamar a atenção para a forma, desviando-se aos poucos do ideal da narração invisível que predominava no período denominado clássico.

Entre os filmes citados por Bordwell (2006) como expoentes da continuidade intensificada estão “Magnolia” (Paul T. Anderson, 1999) e a trilogia “Matrix” (Larry e Andy Wachowski, 1999-2003). Esses filmes contêm tramas com muitos protagonistas, que se desdobram em subtramas paralelas e cronologias complexas, e investem em táticas visuais que fragmentam cada vez mais a ação física das personagens, incluindo a montagem cada vez mais rápida, movimentos incessantes de câmera e a insistência na imagem do rosto humano como maneira de estimular a empatia. A poética da continuidade intensificada também reúne técnicas narrativas e estilísticas que podem ser observadas nos filmes de ficção codificados como found footages, como a câmera na mão que treme sem parar, os "erros" de enquadramento e foco utilizados como tática de encenação, a música de influência concretista (muitas vezes eletrônica, minimalista e sem linha rítmica ou harmônica discernível), os diálogos improvisados e o uso de diferentes tipos de câmeras e texturas imagéticas num mesmo filme. 
Não é coincidência que muitas dessas técnicas sejam oriundas da estilística do documentário, especialmente daqueles de cunho observativo ou participativo (NICHOLS, 2005), mais lembrados pelos espectadores como pertencentes a esse campo. À medida que a plateia está familiarizada com suas técnicas, seu uso reforça a impressão de registro documental das imagens e sons, acentuando a intensidade afetiva das tomadas. Em outras palavras, alguns procedimentos técnicos característicos da continuidade intensificada realizados "à maneira" de certos documentários são capazes de produzir um tipo de efeito de real (BARTHES, 1984, p. 41) mais intenso ao tecido narrativo dos filmes.

Vale a pena chamar a atenção, aqui, para a associação entre os conceitos de continuidade intensificada e efeito do real, pois, segundo Bordwell (2006), uma das razões para a adoção de uma poética cinematográfica maneirista é a busca pelo arrebatamento afetivo e sensorial do espectador. No caso do found footage de ficção, essa poética se transfigura na busca por uma aparência de verossimilhança que permita despertar na plateia um modo particular desse efeito de real, através, inicialmente, da estilística documental e, mais recentemente, da emulação do registro amador.

É neste ponto que propomos a questão de um novo maneirismo que pode estar a nascer. Aceitando a descrição de Prysthon (2013) de que, depois do apogeu do artificialismo autorreferente e metalinguístico dos anos 1990, percebe-se uma espécie de reemergência do realismo em estratégias estilísticas marcadas pelo minimalismo, pelo anticlímax, pelo despojamento e por uma ênfase naturalista chamados hoje de cinema de fluxo (termo também cristalizado pelos Cahiers), notamos, nas obras de Romero e De Palma, uma inflexão diferente dessa busca naturalista.

Tratando do cinema de fluxo, Oliveira Júnior afirma que "na passagem dos anos 1990 para os 2000, época em que se fala no fim do maneirismo, uma nova ferramenta teórica ganha a dianteira: o conceito de 'dispositivo' (2013, p. 137). Como descreve o autor, "no ‘filme-dispositivo', não há mise-en-scene no sentido clássico [...] mas, antes, a definição de uma estratégia visual capaz de produzir acontecimentos por um processo de narração automático". Como descreve o autor, o cineasta agora se torna "um instalador de ambiências, um provocador/intensificador de realidades" (OLIVEIRA JÚNIOR, 2013, p. 138).

Ao fazer uso de alguns dispositivos identificados com práticas do cinema de fluxo, e também do documentário e do audiovisual amador (tais como os tempos mortos e os planos-sequência com câmera na mão, o uso de equipamentos de vigilância e de códigos 
estilísticos de gêneros televisivos como os reality shows), uma atitude maneirista pode estar se dando não mais em relação ao modelo clássico, mas aos procedimentos contemporâneos.

Para Weisbach, "o maneirismo existe quando formas que originalmente tinham um significado preciso e um valor expressivo são retrabalhadas e levadas a extremos" (WEISBACH, 1910 apud BORDWELL, 2006, p. 189). Se, como observa Oliveira Júnior (2013), uma parte do cinema contemporâneo manifesta a tendência de respeitar a ambiguidade do real, explorar o acidental e o assignificante e não impor ao mundo um sentido, talvez se possa sugerir que, em "Diário dos Mortos" e "Guerra sem Cortes", estejamos a assistir, de certa forma, a um arremedo artificial desse tipo de cinema dentro de um campo antes dominado pela ficção convencional. Não por acaso, Baltar e Diogo (2013), em reflexão sobre o apelo emocional das imagens amadoras voltadas à expressão de experiências individuais, destacam a observação de Lipovetsky e Serroy sobre a influência dessas produções em obras comerciais de ficção sobre violência, sexo e horror, que teriam passado por um enfraquecimento em sua lógica narrativa - questão que, parece-nos, interessou a Romero e De Palma em seus filmes de 2007.

\section{Inflexões no estilo: Romero e De Palma, 2007}

Em "Diário dos Mortos" e "Guerra sem Cortes", Romero e De Palma adotaram o projeto estilístico de trabalhar exclusivamente com imagens produzidas dentro da diegese, seja por meio de registros feitos pelas personagens ou encontrados por elas em câmeras de vigilância, programas de televisão, vídeos postados em websites etc. Nos dois casos, os filmes funcionam como inventários de possibilidades para o uso da câmera intradiegética e firmaram-se como referências fundamentais de opções estilísticas dentro do formato. De todo modo, é preciso reconhecer que os experimentos dos diretores se relacionam com seus trabalhos pregressos, tanto em questões temáticas quanto estilísticas.

O filme de Romero é o quinto segmento da série iniciada com "A Noite dos Mortos Vivos" (The Night of the Living Dead, 1968) e encerrada com "A Ilha dos Mortos" (Survival of the Dead, 2009). Nessa série de seis longas, o diretor e roteirista reinventou constantemente os parâmetros do monstro cinematográfico conhecido como "zumbi" tipo de cadáver-redivivo-contagioso que se multiplica em seus filmes e em centenas de 
imitadores desde os anos 1970. Suas imagens nauseantes, porém, nunca esconderam os aspectos políticos, geralmente tão explícitos quanto o sangue e as tripas. E, desde o início, isso foi feito por meio da emulação de estilos estranhos ao horror convencional, como observa Russell sobre "A noite dos Mortos Vivos":

Recusando-se a ladear a questão da materialidade do zumbi [...] Romero trouxe um realismo inflexível ao gênero. [...] A fotografia granulada apoiada pelas cenas de TV com âncoras ansiosos e funcionários públicos desnorteados em Washington — dá ao filme um visual cinéma verité, sugerindo que esses acontecimentos não fazem parte de um terror "sobrenatural". [...] A cotidianidade é a chave para o terror do filme (RUSSELL, 2012, p. 111-112).

Essa adoção de um estilo até então inédito no horror foi uma marca da influência de Romero, mas suas características maneiristas são mais evidentes em filmes que não pertencem à série dos mortos-vivos, como "Martin" (1977) 4 , filme "realista" de vampiro em que um jovem bebedor de sangue compara seu cotidiano às representações tradicionais dos vampiros, e no longa em episódios "Creepshow" (1982), no qual Romero aproveitou suas origens como diretor de publicidade para brincar com a linguagem dos quadrinhos e com a TV, além de já experimentar algumas cenas feitas com câmeras de vigilância.

Caso diferente é o de De Palma, diretor que dedicou sua carreira a investigar o estatuto da imagem cinematográfica e suas tradições de maneira muito mais estrutural do que Romero.

No que se refere às questões temáticas, os acontecimentos históricos que inspiraram "Guerra sem Cortes" - o estupro de uma adolescente e o assassinato brutal dela e de sua família por soldados estadunidenses no Iraque em 2006 — repetem um assunto que já interessara ao diretor em um filme sobre a guerra do Vietnã: "Pecados de Guerra" (Casualities of War, 1989). Além do tema específico do estupro/massacre, pode-se relacionar "Guerra sem Cortes" à reflexão mais ampla sobre a misoginia e a brutalização das mulheres vistas na obra de De Palma, em filmes como "Carrie a Estranha" (Carrie, 1977), "Vestida para Matar" (Dressed to Kill, 1982), "Dália Negra” (The Black Dhalia, 2005), entre outros.

\footnotetext{
${ }^{4}$ Quanto a esse filme, vale lembrar que ele foi inteiramente refeito entre 1976 e 1977, já que os negativos originais foram roubados com um furgão da equipe, obrigando o diretor a refazer o trabalho.
} 
Já do ponto de vista das escolhas estilísticas, é preciso reconhecer que quase toda a obra de De Palma enfrenta a questão da produção de imagens intradiegéticas, o que o torna peça fundamental nesta discussão. Desde seus primeiros trabalhos mais conhecidos (Greetings, 1968, e principalmente Hi Mom!, 1970), passando por “O Fantasma do Paraíso" (Phantom of the Paradise, 1974), "Terapia de Doidos” (Home Movies, 1980), "Um Tiro na Noite" (Blow Out, 1982) e "Passion" (2012), dispositivos variados de produção de imagens e sons incorporados à diegese são marcas não apenas do virtuosismo, mas também da reflexão sobre o cinema recolocada constantemente pelo diretor.

Ainda que se trate de cineastas difíceis de comparar, De Palma e Romero compartilhavam algumas circunstâncias em 2007. Apesar da fama e do reconhecimento, ambos se encontravam em condições economicamente menos favoráveis, em termos de recursos de produção, do que muitos de seus colegas de geração cujas carreiras têm paralelos com as deles, como Wes Craven e Martin Scorsese. Dessa constatação se pode inferir que o risco assumido pela atitude experimental derivou, em parte, da ausência de projetos ligados aos grandes estúdios, e talvez mesmo da limitação de recursos, problema que pode ser contornado pelo uso da câmera intra-diegética em condições "amadorísticas". O filme de De Palma custou cinco milhões de dólares (10\% do orçamento de seu filme anterior, o fracasso comercial "Dália Negra"), e o de Romero custou apenas dois milhões (15\% do orçamento de "Terra dos Mortos", de 2004, outro malogro comercial). Mesmo assim, nenhum rendeu o suficiente para cobrir os próprios custos.

Os dois projetos possuem premissa similar. Ao contrário da maior parte das produções codificadas como found footage conduzidas em meados dos anos 2000, "Guerra sem Cortes" e "Diário dos Mortos" não escondem do espectador a natureza ficcional de seus sons e imagens. Quem vê os filmes é capaz de indexá-los à categoria de ficção sem qualquer dificuldade, já nos primeiros segundos de projeção.

Romero realiza essa operação logo na sequência de abertura, através de uma colagem de trechos de reportagens falsas de TV (Figura 1) que expõe o ponto de partida do enredo: a doença que faz mortos voltarem à vida e atacarem os vivos, lançando o mundo no caos. É uma premissa tão absurda e já codificada ao subgênero dos zumbis que elimina qualquer possibilidade de indexação documental. De Palma é ainda mais resoluto, pois "Guerra sem Cortes" inicia com uma tela cujo texto informa ao espectador de que ele verá "um trabalho de ficção, inspirado por eventos supostamente ocorridos no Iraque” (Figura 2). Essa primeira linha contém uma dupla tentativa de afastar o filme da leitura documentarizante, 


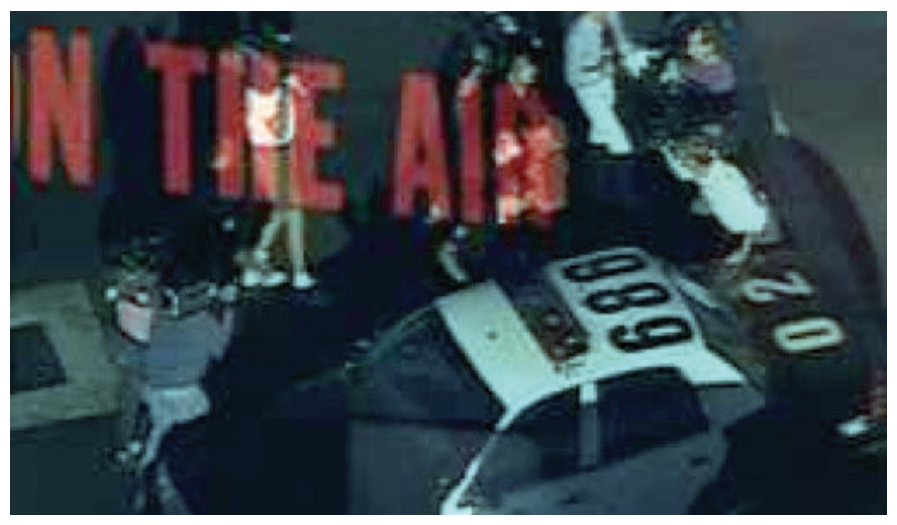

Figura 1. Abertura de "Diário dos Mortos"

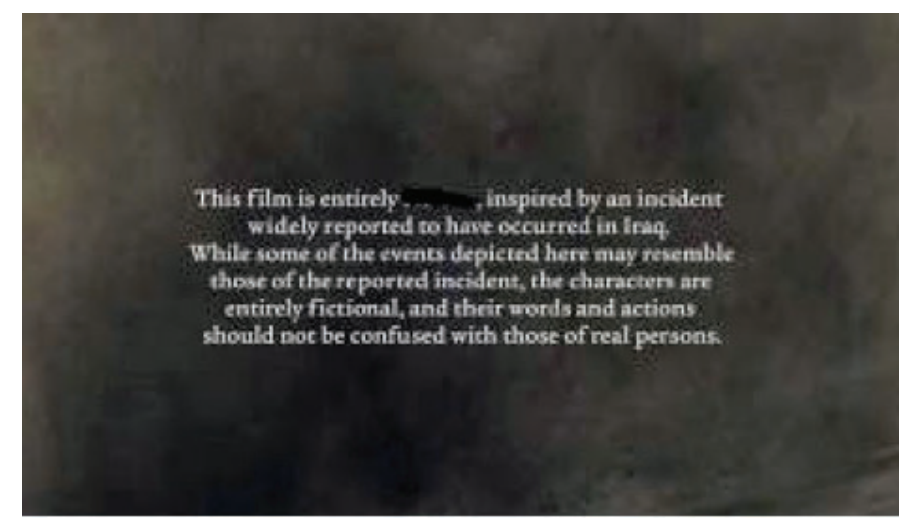

Figura 2. Início de "Guerra sem Cortes"

pois assegura que as imagens são encenadas por atores e reforça que os fatos não foram confirmados por qualquer fonte oficial.

Isso posto, a forma como os diretores lidam com o instrumental estilístico reflete uma atitude que pode ser tratada como maneirista. Os dois respeitam o tempo inteiro as restrições impostas pelo princípio da câmera intradiegética (CARREIRO, 2013): a fisicalidade dos dispositivos de registro inseridos na diegese impede a ubiquidade da instância narradora e limita a forma como as ações físicas das personagens são gravadas, já que as câmeras não podem estar ligadas o tempo inteiro e existem locais e momentos que esses dispositivos não conseguem ou não podem acessar. Cada cineasta, contudo, recorre a expedientes distintos para driblar essa restrição e alargar o ponto de vista narrativo.

De Palma transforma seu filme em uma colagem de registros provenientes de diferentes fontes: vídeo-diários de soldados, trechos de um documentário da TV francesa, 
câmeras de segurança, vídeos amadores disponibilizados na Internet e até mesmo pedaços de conversas travadas em sistemas de comunicação similares ao Skype (Figura 3). Essa estratégia torna-o capaz de construir um enredo em que o narrador invisível substitui, pelo menos em parte, a ausência da ubiquidade da câmera por uma espécie de ubiquidade do ponto de vista, já que a instância narrativa permanece parcialmente onisciente. Também há a construção de personagens muito falantes, que comentam constantemente seus sentimentos e intenções, além do texto informativo do programa da TV francesa, o que permite ao filme desenvolver suas questões de forma progressiva e explícita.

Já Romero adota uma construção mais comum em filmes de found footage ficcional, nos quais a instância narradora espelha a perspectiva alternada de dois personagens (Figura 4). O primeiro é Jason Creed (Joshua Close), estudante de cinema que, ao se deparar com mortos voltando à vida, decide registrar a realidade e editar um documentário, cujo work in progress divulga na Internet. Quando ele morre, a namorada Debra (Michelle Morgan) assume a direção e inclui, nos trechos editados por ele, sua narração em voz over e trechos de filmes gravados de câmeras de segurança ou encontrados na Internet. Há, portanto, uma dupla estratégia narrativa colocada em operação para minimizar o estreitamento produzido pela câmera intradiegética.

A primeira tática consiste na inclusão da narração verbal, que permite a Debra comentar e ressignificar as imagens, usando a trilha de voz como contraponto à trilha visual. A segunda tática consiste no uso de metalinguagem: Romero alterna os registros audiovisuais do apocalipse zumbi com sequências em que os personagens discutem as imagens, explicam os detalhes técnicos, refletem sobre opções estilísticas e debatem, de maneira por vezes grandiloquente, a situação trágica em que se encontram.

Mas talvez o aspecto em que a abordagem maneirista de Romero e De Palma esteja mais visível seja o uso abundante de planos-sequência. A estratégia de usar tomadas mais longas também deriva do princípio da câmera intradiegética, pois, como o dispositivo de registro está presente na diegese, o diretor tem mais dificuldade para fazer cortes e mudar a posição da câmera durante uma cena. No entanto, como convém a dois diretores que exercem um amplo domínio sobre a imagem, Romero e De Palma não resistem a encenar cuidadosamente os planos mais importantes, mostrando e escondendo elementos visuais dentro do quadro com eficiência incompatível com a precariedade de um registro visual e sonoro improvisado.

“Diário dos Mortos" tem 379 planos distribuídos em 89 minutos, o que significa uma duração média de plano de 14 segundos, número quase 4 vezes maior do que a média 


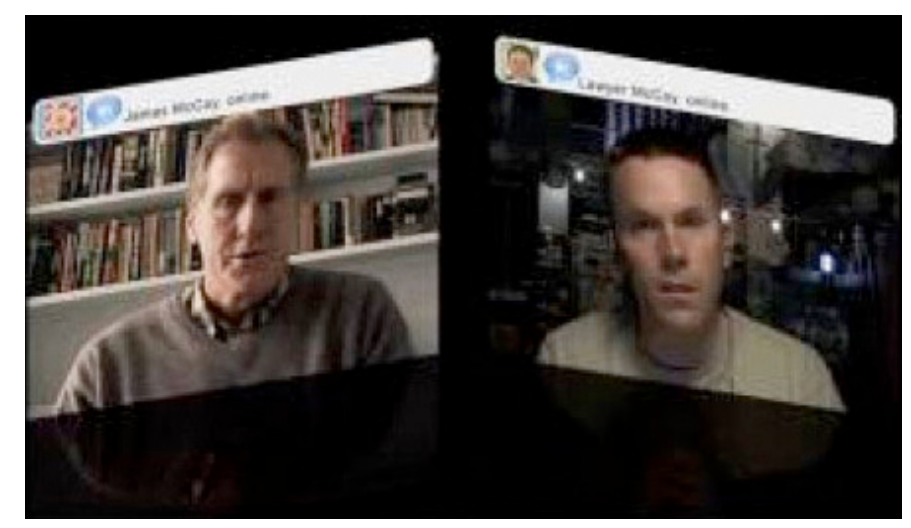

Figura 3. O plano mais longo de "Guerra sem Cortes"

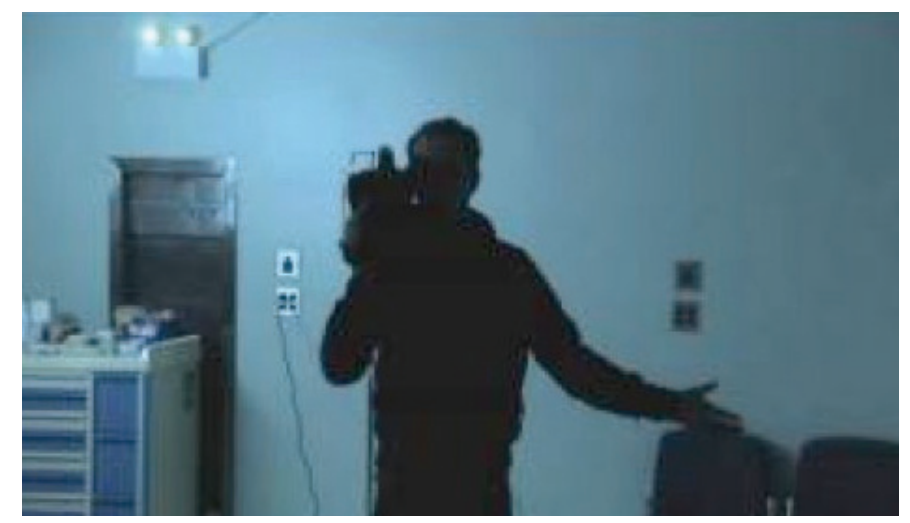

Figura 4. Duas câmeras simultâneas em "Diário dos Mortos"

praticada nos filmes de Hollywood desde os anos 1990 (SALT, 2009). O filme de Romero tem 17 planos com duração superior a 1 minuto, e o mais longo, com 182 segundos, ocorre ainda no início do filme, no momento em que Romero apresenta seus protagonistas ao espectador num set de filmagens localizado num bosque. A tomada chama a atenção pela encenação composta meticulosamente: mesmo operada manualmente, a câmera possui estabilidade, enquanto seu operador caminha para frente, para trás e para os lados, sempre reenquadrando os rostos de quem fala. Já os atores caminham em eixos diagonais, explorando a profundidade de campo e criando uma coreografia de corpos complexa e nada gratuita (Figura 5). Nenhuma ação física importante para a compreensão da cena ocorre fora do quadro, ou em enquadramentos que bloqueiem a visão do espectador.

Em “Guerra sem Cortes”, De Palma aplica o rigor de seu virtuosismo à tarefa de construir a aparência de erros técnicos em cenas e sequências que não prejudiquem a 
compreensão do enredo. O filme possui apenas 141 planos em 80 minutos, alcançando uma duração média de 34 segundos. Existem 20 planos maiores do que 1 minuto, sendo que 11 têm mais de 2 minutos de duração. O plano-sequência mais longo dura 416 segundos e traz para o universo da diegese a famosa técnica da tela dividida (split screen), que constitui uma das assinaturas estilísticas mais proeminentes de De Palma desde os anos 1970: trata-se do plano que mostra pai e filho conversando através do Skype (Figura 3). Note-se que esse é um plano artificial, composto pela instância narradora sem qualquer interferência dos personagens. Nas tomadas longas, De Palma também recorre frequentemente à estratégia da encenação em diagonal, com a maior parte da ação ocorrendo dentro do quadro (Figura 6).

Também vale notar que o cineasta varia o tipo de lente, a colorimetria e a composição visual dos diferentes segmentos do filme, dependendo da origem de cada grupo de imagens.

As tomadas oriundas das câmeras operadas pelos soldados, por exemplo, têm resolução visual mais baixa, cores mais desbotadas e pouca profundidade de campo (Figura 7); muitas vezes, esses planos constituem tomadas com câmera fixa, colocada sobre uma cadeira (Figura 6) ou o capô de um carro. Já os trechos do documentário francês (Figura 8) têm coloração dourada, e os movimentos de câmera são suaves e profissionais.

Nos dois filmes, é possível perceber, também, a valorização ou elogio do erro técnico. Trata-se de mais uma característica herdada do princípio da câmera intradiegética: as imagens não vão se parecer com registros casuais de situações extraordinárias caso não contenham esses defeitos aparentes, como certa falta de estabilidade, ações inesperadas e cortes bruscos. Nem Romero e muito menos De Palma, contudo, alcançam um nível de crueza e sujeira audiovisual compatível com um registro verdadeiro feito no calor da hora. Os erros técnicos não surgem espontaneamente, mas são calculados e, portanto, virtuosos. Até mesmo as imagens oriundas de câmeras de vigilâncias são cuidadosamente compostas e enquadradas (Figuras 9 e 10).

Essa espécie de virtuosismo às avessas está ainda mais evidente nas trilhas de áudio dos filmes, cujos diálogos são sempre claros, limpos e perfeitamente audíveis. Há efeitos sonoros organizados metodicamente e seguindo preceitos tradicionais da edição de som (por exemplo, o filme de Romero inicia com uma sirene de polícia estrategicamente colocada na abertura do primeiro plano, a fim de sinalizar rapidamente ao espectador a urgência "documental" daquele momento). Um ouvido treinado percebe o uso de manipulações técnicas oriundas do tratamento acústico, inclusive compressão e reverberação, a fim de manter vozes e ruídos dentro de um padrão de áudio confortável e legível. Por fim, os dois cineastas utilizam música não diegética, 


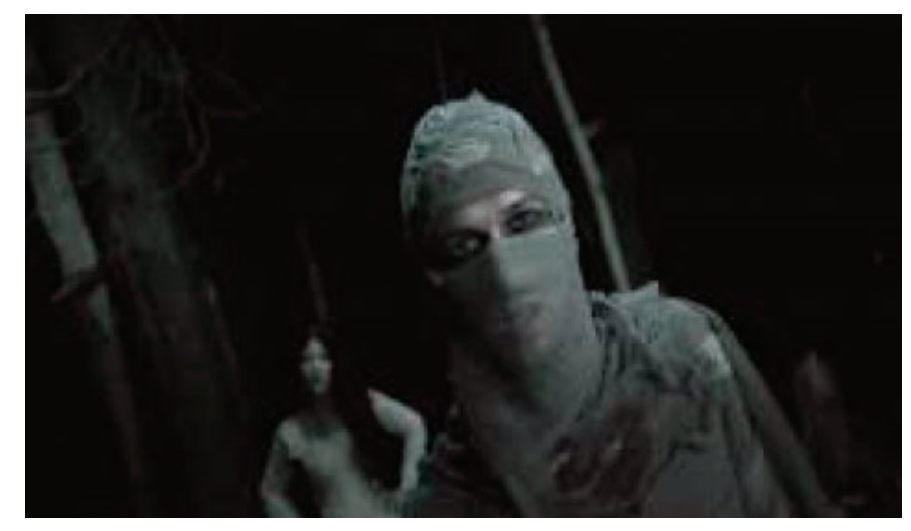

Figura 5. Encenação em diagonal em "Diário dos Mortos"

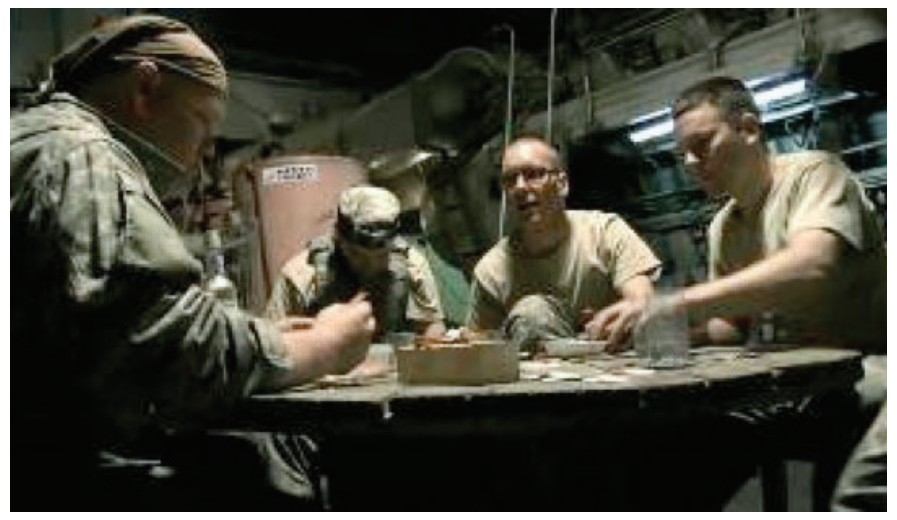

Figura 6. Composição recessiva em "Guerra sem Cortes"

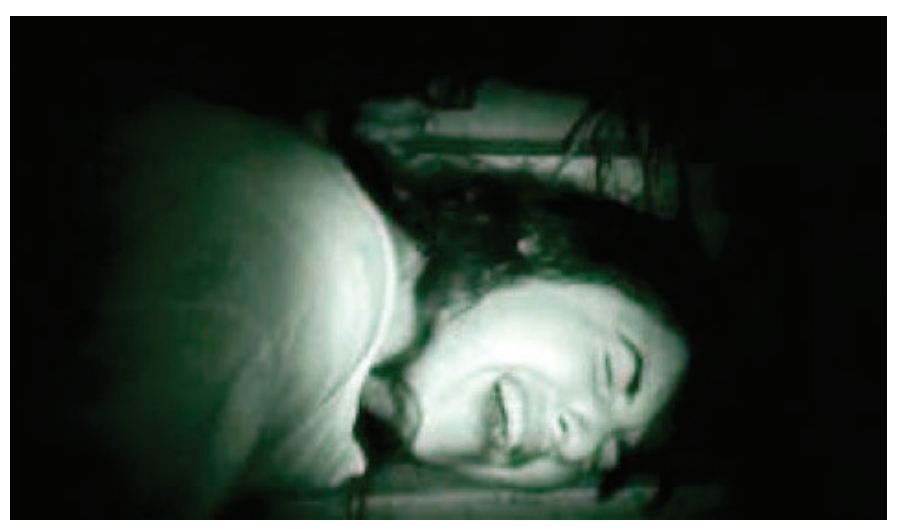

Figura 7. Imagem sem profundidade em "Guerra sem Cortes" 


\section{Contracampo}

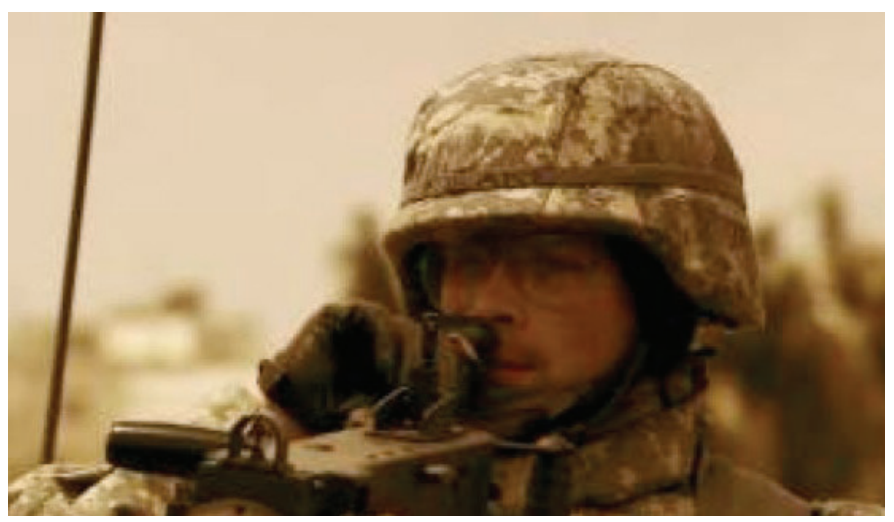

Figura 8. Tomada com câmera fixa em "Guerra sem Cortes"

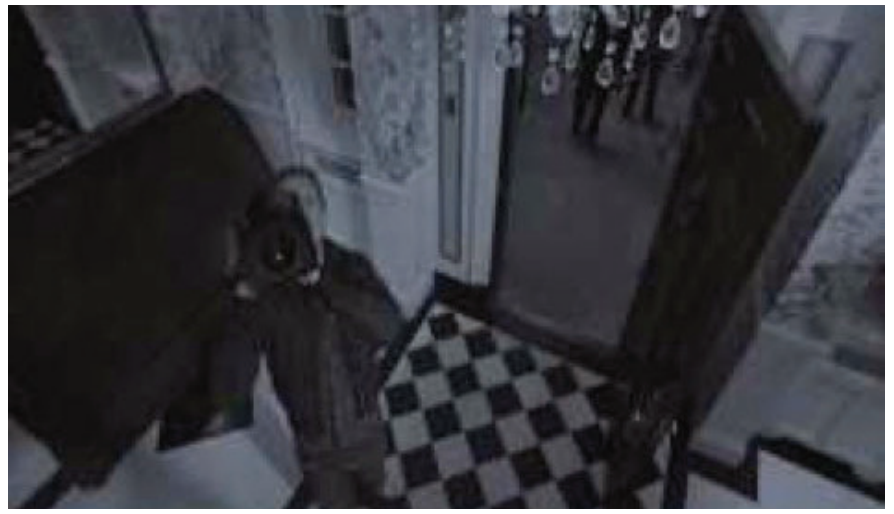

Figura 9. Câmera de segurança em "Diário dos Mortos"

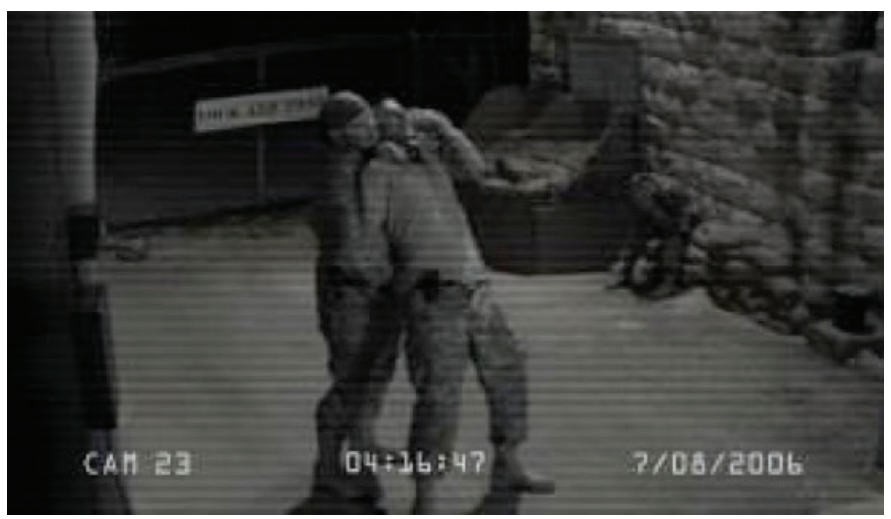

Figura 10. Imagem de câmera de segurança em "Guerra sem Cortes" 
padrão típico do cinema de ficção tradicional que eles não se preocupam em esconder, porque, afinal, assumem desde o princípio seus filmes como ficções que apenas emprestam a técnica do documentário e do registro amador, sem pretender se fazer passar por nenhum deles.

\section{Conclusões}

Como vimos, a produção de filmes de ficção codificados como found footage ganhou fôlego a partir do sucesso de crítica e público alcançado por “A Bruxa de Blair”. Os cineastas que exploraram o formato a partir do ano 2000 não realizaram grandes inovações formais de imediato. Muitos eram novatos, trabalhando com orçamentos limitados. Diante desse panorama, as soluções para os problemas de representação introduzidos pelo princípio da câmera intradiegética demoraram a alcançar alguma originalidade formal.

É nesse ponto que entram os filmes de Romero e De Palma. Veteranos acostumados a experimentar novas tecnologias e ferramentas de estilo, eles parecem ter encontrado uma oportunidade para revitalizar suas reflexões formais iniciadas nos anos 1960. Nos dois trabalhos, os diretores exploram técnicas diversas, na tentativa de solucionar questões de representação introduzidas no enredo porque as personagens da ficção têm consciência dos dispositivos de registro dentro da diegese, bem como tentam minimizar os limites estreitos para a representação impostos por essa presença.

Para além dos experimentos com forma e narrativa dos filmes, os diretores também introduziram certa dimensão crítica aos novos processos de midiatização e regimes de visualidade que privilegiam ou valorizam imagens amadoras, cenas de exposição da intimidade e a proliferação de dispositivos de registro visual. É possível dizer que tanto "Diário dos Mortos" quanto "Guerra sem Cortes" discutem o papel das mídias ao mostrarem que, graças à existência de câmeras de segurança, telefones celulares com filmadoras e outros dispositivos espalhados por ruas, casas, hospitais etc., a privacidade tem se tornado uma dimensão cada vez menos possível — e talvez menos almejável — na vida das pessoas.

Em certa medida, por fim, podem-se ler ambos os filmes como releituras atualizadas de trabalhos anteriores. "Guerra sem Cortes" funciona como uma espécie de refilmagem de "Pecados de Guerra", acrescida de reflexão crítica sobre a enorme quantidade de imagens que circulam livremente, enquanto "Diário dos Mortos" pode ser visto como remixagem 
de "A Noite dos Mortos Vivos", tendo a ação dramática deslocada para um micro-ônibus, com as câmeras nas mãos das personagens.

Para Barry Keith Grant, obras como essas (as quais ele classifica como new verité) são sintomáticas de uma sensibilidade pós-moderna que, na era digital, coloca em dúvida o estatuto de verdade de "qualquer" imagem (2013). Nesse sentido, Alexandra HellerNicholas oferece uma explicação sucinta para mostrar a relação entre o realismo das imagens e sons e o fascínio exercido por esses filmes sobre o público:

A tradição do found footage de horror evoluiu e amadureceu [desde "A Bruxa de Blair"], e por sua vez o público pode se envolver com os filmes de modo mais consciente, sem tomá-los por documentários reais. O prazer gerado pela estilística do gênero não é dependente da nossa credulidade, mas sim da nossa vontade de sucumbir ao "mito do real" que esses filmes oferecem através de seu sistema formal, agora fortemente codificado (HELLER-NICHOLAS, 2014, p. 27).

Pensar sobre esses filmes a partir do impulso maneirista presente nas obras de Romero e De Palma pode contribuir para a reflexão sobre a incorporação de estratégias experimentais contemporâneas ao cinema de ficção comercial, fenômeno que deve ser observado com atenção à medida que reflete os novos regimes de visualidade em suas formas mais populares.

\section{Referências}

ALTMAN, Rick. Film/genre. London: BFI Publishing, 1999.

BALTAR, Mariana; DIOGO, Lígia. Viver conectado. In: BRASIL, André; MORETTIN, Eduardo; LISSOVSKY, Maurício (Orgs.). Visualidades hoje. Salvador: EDUFBA, 2013. p. 137-156.

BARTHES, Roland. O rumor da língua. Lisboa: Edições 70, 1984.

BORDWELL, David. The way Hollywood tells it: story and style in modern movies. Los Angeles: University of California Press, 2006.

BORDWELL, David. Sobre a história do estilo cinematográfico. Campinas: Editora da UNICAMP, 2013. 
BRASIL, André; MIGLIORIN, César. Biopolítica do amador: generalização de uma prática, limites de um conceito. Galáxia, São Paulo, n. 20, p. 84-94, dez. 2010.

CÁNEPA, Laura; FERRARAZ, Rogério. Fantasmagorias das imagens cotidianas. In: BRASIL, André; MORETTIN, Eduardo; LISSOVSKI, Mauricio (Orgs). Visualidades Hoje. Salvador, EDUFBA/COMPÓS, 2013, p. 79-100.

CARREIRO, Rodrigo. A câmera diegética: legibilidade narrativa e verossimilhança documental em falsos found footage de horror. Significação, São Paulo, n. 40, p. 224-244, 2013.

FELDMAN, Ilana. O apelo realista: uma expressão estética da biopolítica. In: ENCONTRO ANUAL DA COMPÓS, 17., 2008, São Paulo. Anais eletrônicos... São Paulo: UNIP, 2008. Disponível em: $<$ http://www.compos.org.br/data/biblioteca_359.pdf $>$. Acesso em: 02 jul. 2014.

GOMBRICH, Ernst. A história da arte. Rio de Janeiro: LTC, 1999.

GRANT, Barry Keith. Digital anxiety and the new verité horror and sf film. Science Fiction Film and Television, v. 6, n. 2, p. 153-175, Summer 2013.

HAUSER, Arnold. História social da arte e da literatura. São Paulo: Martins Fontes, 2000.

HELLER-NICHOLAS, Alexandra. Found footage horror films: fear and the appearance of reality. London: McFarland, 2014.

MACHADO, Arlindo. O sujeito na tela: modos de enunciação no cinema e no ciberespaço. São Paulo: Paulus, 2007.

NICHOLS, Bill. Introdução ao documentário. Campinas: Papirus, 2005.

ODIN, Roger (Org.). Le film de famille: usage privé, usage public. Paris: MéridiensKlincksieck, 1995.

OLIVEIRA JÚNIOR, Luiz Carlos. A mise en scène no cinema: do clássico ao cinema de fluxo. Campinas: Papirus, 2013.

PRYSTHON, Angela. Efeitos do real no cinema do mundo. In: BRASIL, André; MORETTIN, Eduardo; LISSOVSKY, Maurício (Orgs). Visualidades hoje. Salvador: EDUFBA, 2013. p. 101-117.

RUSSELL, Phil. Beyond the darkness: cult, horror and extreme cinema. New York: Bad News Press, 2012.

SALT, Barry. Film style \& technology: history and analysis. London: Stardword, 2009.

SHEARMAN, John. Mannerism: style and civilization. Harmondsworth: Penguin, 1967. 